\title{
Assessing Impervious Surface Changes in Sustainable Coastal Land Use: A Case Study in Hong Kong
}

\author{
Kapo Wong ${ }^{1}$, Yuanzhi Zhang ${ }^{1,2,3, *}$, Jin Yeu Tsou ${ }^{1}$ and $\mathrm{Yu} \mathrm{Li}^{4, *}$ \\ 1 Center for Housing Innovations, The Chinese University of Hong Kong, Shatin, New Territories, \\ Hong Kong, China; wongkapoportia@gmail.com (K.W.); jinyeutsou@cuhk.edu.hk (J.Y.T.) \\ 2 National Astronomical Observatories, Chinese Academy of Sciences, Beijing 100012, China \\ 3 Key Lab of Lunar Science and Deep-Space Exploration, Chinese Academy of Sciences, Beijing 100012, China \\ 4 Faculty of Information Technology, Beijing University of Technology, Beijing 100124, China \\ * Correspondence: yuanzhizhang@cuhk.edu.hk (Y.Z.); yuli@bjut.edu.cn (Y.L.); Tel.: +852-6225-4062 (Y.Z.)
}

Academic Editors: Hualin Xie and Yanni Yu

Received: 28 April 2017; Accepted: 9 June 2017; Published: 15 June 2017

\begin{abstract}
In Hong Kong, reclamation is the main method for developing new land use areas as most country parks and mountains are protected under a land policy that emphasizes conservation for their high ecological value. Therefore, the land use for urbanized area in Hong Kong is limited, which has become an issue of concern. Hong Kong's population is increasing; however, the amount of available land use is insufficient to meet the demand. Developing a high density of buildings is one of the critical strategies of Hong Kong's government. Highly dense development may result in an urban heat island as well as health problems. In this study, we present an assessment of urban impervious surface changes in coastal megacities like Hong Kong based on satellite images. Landsat satellite images are employed to analyze urban impervious surface changes from 1995 to 2015 in coastal urban areas of Hong Kong. The results show that the increase of impervious surface area is almost the same as the increase in land reclamation area. This suggests that Hong Kong's land use policy, which underlines conservation for high ecological value and reclamation, may be able to maintain its sustainable development of coastal land use.
\end{abstract}

Keywords: impervious surface; sustainable land use; coastal megacities; satellite images; Hong Kong

\section{Introduction}

Impervious surface [1] is a water resistant surface contributing to the assessment of the urbanization [2]. Impervious surface can be found in the rooftops, roads and various infrastructures. Urbanization is a term that describes the state where more people are moving into the city due to economic factors or other reasons. Many infrastructures are built during the process of urbanization; the amount of impervious surface therefore continues to increase as more residential buildings, business centers and associated facilities are built to meet the demands of the growing population.

Remote Sensing has been widely applied to assess the impervious surface [3-5] with the rapid development of the earth observation satellites. Starting in the 1970s, the Landsat Thematic Mapper (TM) was introduced and remote sensing technology has become highly developed since that time. Since the late 1980s and early 1990s, the ESA (European Space Agency), SPOT (Systeme Probatoire d'Observation de la Terre), IRS (Indian Remote Sensing Satellite System), and IERS (Japanese Earth Resource Satellite) have also launched new satellites to support a wide variety of environmental analyses [5] such as monitoring land use and land cover changes and analyzing urban environmental changes.

The V-I-S (vegetation-impervious-soil) model [3,6-9] was proposed as the fundamental tool for the urban analysis. The V-I-S model was used to identify three compositions on land, including 
vegetation, impervious surface and soil, and the composition of water was ignored with regarding to the model. The V-I-S model can only be the basis for a general analysis; while the earth contains various kinds of materials and land types, but the V-I-S model cannot classify them all. The usefulness of identifying the land types could explain the effect of urbanization as the impervious surface has an interdependent relationship with the urbanization. A modified model, V-H-L-S model (vegetation-high albedo-low albedo-soil) [10-12], was developed that divided the impervious surface into high albedo and low albedo. A broad difference of spectral characteristics could be identified through the V-H-L-S model.

In the V-H-L-S model, Minimum Noise Fraction (MNF) is used to optimize the data dimensionality, which is adjusted by the Principle Component Analysis (PCA) [6]. The reduction of noise in the Landsat image is to enhance the significant features on the image. The eigenvalues of each band can be obtained from the MNF transform. The highest value of the eigenvalue of the MNF band indicates a favorable spatial feature for endmember selection. The eigenvalue should be greater than 1.0. The process of MNF transform is a crucial step in the estimation of impervious surface estimation. The land use and land cover change could be identified after processing the V-H-L-S model of different periods. Land use and land cover change recorded the significant regional anthropogenic disturbance to the environment [13-15].

Although the V-I-S model has been widely used to estimate urban impervious surface in many previous studies [16-18], there is little literature about monitoring the impervious surface changes in Hong Kong as observed from satellite images. As a coastal megacity, Hong Kong has been selected as the study area because the area has undergone the process of urbanization over the past 20 years. Due to the land policy that emphasizes environmental conservation, the change in the impervious surface area of Hong Kong has been small. In this study, the change in the impervious surface of Hong Kong has been determined based on the Landsat TM5 and Landsat TM8 images. The Landsat TM images have been processed using the V-H-L-S model analysis and Linear Spectra Mixing analysis after selection of endmembers.

In Hong Kong, the land policy emphasizes ecological protection [19-21] and reclamation. Reclamation enhances the innovative value in sustainable coastal land use management. The Town Planning Ordinance prepared town plan with statutory land use to promote conservation or protection for country parks, coastal protection areas, sites of special scientific interest, green belts or other specified use [22]. The management of the coastal protection areas was to conserve, protect, and retain the natural coastlines and the sensitive coastal natural environment. Praya Reclamation Scheme was one of the earliest reclamation projects in the 1860s. The reclamation project was to stabilize the new coastline against coastal erosion and most reclaimed areas such as Tuen Mun, Tai Po, and Kai Tak Airport were developed as urbanized areas, which are impervious surface now. Impervious surface estimation was calculated to determine the amount of change in Hong Kong. Estimation of the change of impervious surface area in Hong Kong over the past twenty years can indicate whether the land use strategy is sufficient to meet the requirement for land and lead to suggestions for sustainable land use [23-25] in coastal megacities in the long term. Coastal megacities are the cities threatened by the specific impacts of climate change [26-28]. Therefore, it is necessary to assess impervious surface changes in coastal urban areas in Hong Kong.

\section{Study Area and Data}

\subsection{Study Area}

Hong Kong, located at $22.3964^{\circ} \mathrm{N}$ and $114.1095^{\circ} \mathrm{E}$ (Figure 1), is a special administrative region with $2755 \mathrm{~km}^{2}$ of total area [29], including land and sea areas. The land area of Hong Kong is mainly composed of New Territories, Kowloon Peninsula and Hong Kong Island. According to the census and statistics for Hong Kong in 2015 [29], most of the land covers in Hong Kong are grassland, agricultural land, and mountainous trees or shrubs. Hong Kong also has a hilly characteristic that means there 
are many mountains in Hong Kong. Reclamation is the main strategy to increase land use for new building areas because most of the country parks have a high ecological value, which cannot be used for any other purposes of land use.

Hong Kong has a free economic market and favorable economic development; therefore, many young people come to Hong Kong to seek a new life. Hong Kong is undergoing urbanization as the total population in 2017 is about 7.40 million and the population is increasing at a rate of about $0.75 \%$ to $0.85 \%$. Under the conditions of increasing population and almost unchanged land area, density in Hong Kong is extremely high. The estimation of the change of impervious surface areas in Hong Kong over the past twenty years can be helpful in understanding whether the land-use strategy is sufficient in Hong Kong in the long term.

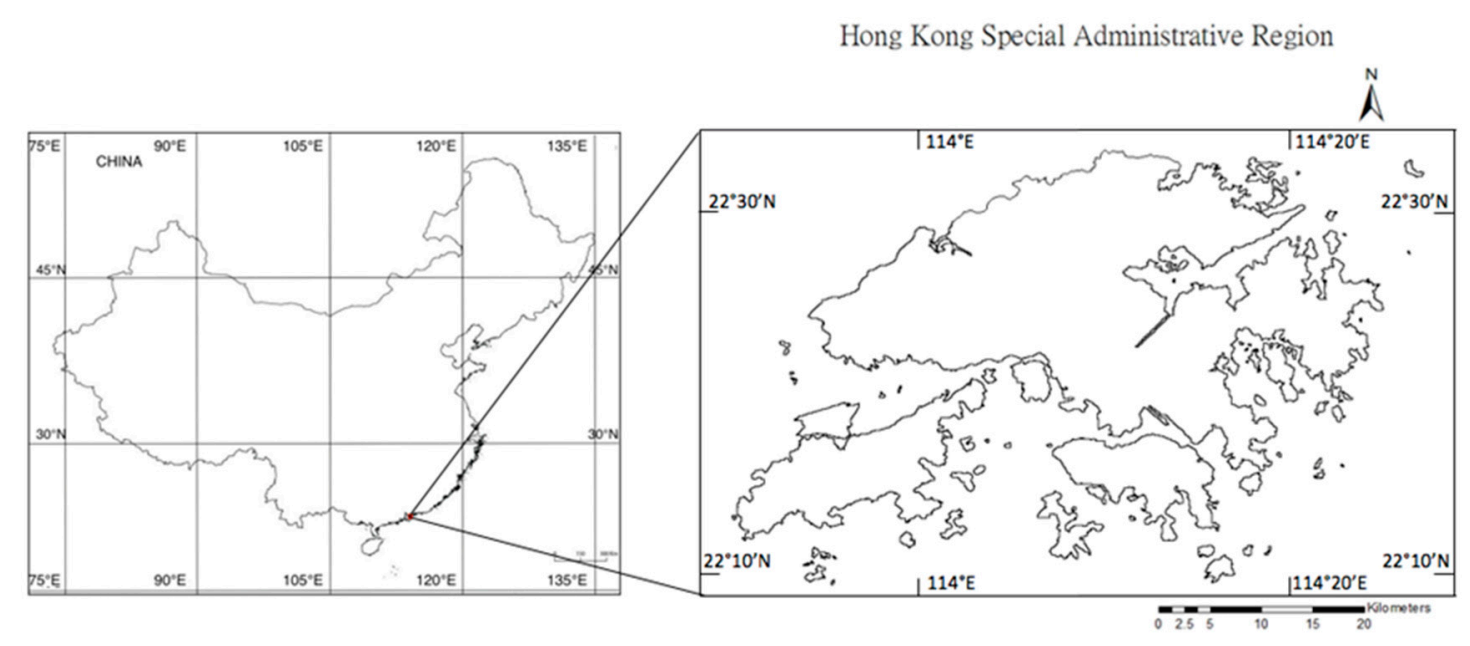

Figure 1. Study Area in Hong Kong.

\subsection{Data Collection}

The Landsat Thematic Mapper (TM) images for the study were collected in 1995, 2004 and 2015. Landsat TM5 images have been applied for in study for 1995 and 2004, while Landsat TM8 images have been applied in the study for 2015. In order to extract the most cloud-free Landsat TM images, 2 November 1995, 29 November 2004, and 8 August 2015 have been adopted in the study area (Table 1). The sensor altitude is $705 \mathrm{~km}$, with a spatial resolution of $30 \mathrm{~m}$.

Table 1. Data Information.

\begin{tabular}{ccccccccccccc}
\hline & \multicolumn{4}{c}{1995} & \multicolumn{2}{c}{ 2004 } & \multicolumn{4}{c}{2015} \\
\hline Date & \multicolumn{3}{c}{ 2 November 1995 } & \multicolumn{3}{c}{ 29 November 2004 } & \multicolumn{4}{c}{ 8 August 2015 } \\
Sensor Type & \multicolumn{3}{c}{ Landsat TM5 } & \multicolumn{3}{c}{ Landsat TM5 } & \multicolumn{3}{c}{ Landsat TM8 } \\
Path & 210 & 210 & 220 & 220 & 210 & 210 & 220 & 220 & 210 & 210 & 220 & 220 \\
Row & 44 & 45 & 44 & 45 & 44 & 45 & 44 & 45 & 44 & 45 & 44 & 45 \\
\hline
\end{tabular}

\section{Methods}

Figure 2 shows the procedure from image processing to the extraction of impervious surface. Landsat TM images were downloaded from the USGS website and then extracted in the ENVI software. Atmospheric correction should be carried out to adjust the visibility of the Landsat TM image and a high-level visibility of the image should be favorable to conduct the further data processing. The region of Hong Kong on the Landsat TM images was set as the region of interested (ROI) in the ENVI software. The water part surrounding and inside the Hong Kong region should be masked first to assess an accurate impervious surface estimation. After creating a water mask for the Hong Kong 
Landsat TM images, Minimum Noise Fraction (MNF) transform was conducted to remove the noise fraction. The results of the first three MNF bands were selected for the 2D scatter plot for selection of endmembers, in which four types of endmembers could be selected through the linear triangle formed on the 2D scatter plot. The four endmembers were vegetation, high albedo, low albedo, and soil. The selected endmembers could be input into the linear spectral un-mixing analysis, and five layers popped up. The first four layers were the fraction of each endmember, and the fifth layer was the root mean square (RMS) result that indicated the accuracy of the data extraction. The combination of high albedo and low albedo was the result of impervious surface. In order to assess accuracy, the Google Earth images could be used to assess the impervious surface fraction. Finally, an analysis of the change in impervious surfaces was conducted.

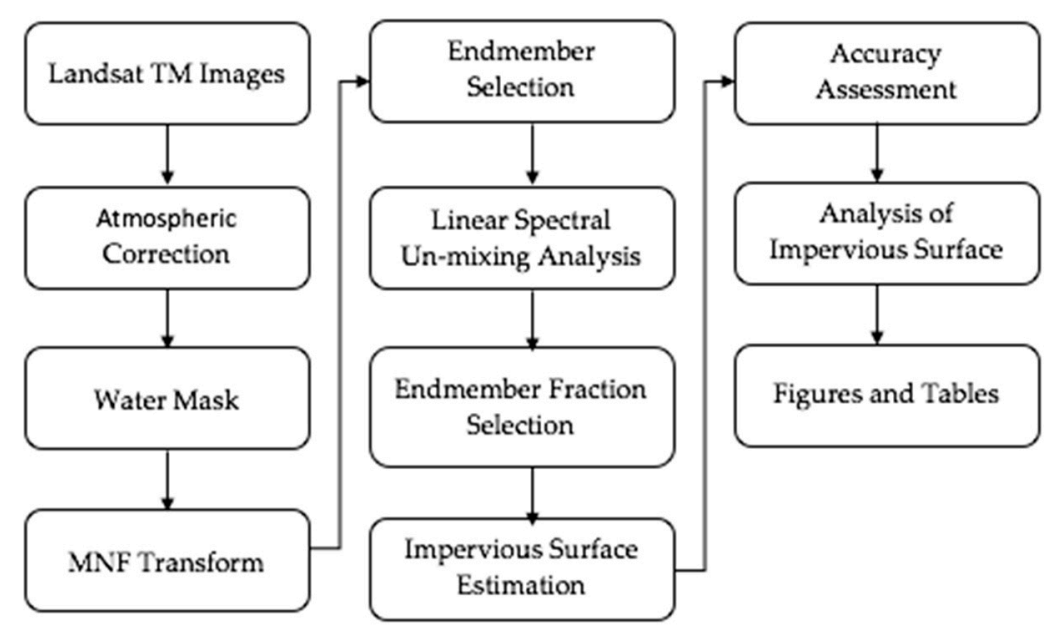

Figure 2. The procedure of impervious surface estimation.

\subsection{Linear Spectral Mixture}

The Linear Spectral Mixture (LSM) model is used to calculate each fraction of endmembers in a pixel [11]. The LSM model generally describes the mixed compositions of land type covers with the pure endmember using the following equation. The formula for the LSM model [30] is:

$$
\begin{gathered}
R_{i}=R \sum_{i=1}^{N} f_{m} R_{m i}+e_{i} \\
\sum_{m=1}^{N} f_{m}=1 ; f_{m} \geq 0
\end{gathered}
$$

where $R_{i}$ is the total reflectance for band $i$ in the Landsat image. $N$ is the total number of endmembers and $f_{m}$ is the fraction of endmember $m . R_{m i}$ is the reflectance of the endmember $m$ in the band $i$, and $e_{i}$ is the unwanted residual [31,32].

Previous studies reported that about two to six endmembers could be selected from the linear spectral mixture model [33]. Minimum Noise Fraction (MNF) transform [34] was employed for image processing to remove noise in the image and enhance the data dimensionality. The eigenvalue with higher values could be applied to the endmember selection process based on the 2D scatter plot. Generally, MNF Band 1, MNF Band 2, and MNF Band 3 were chosen for the 2D scatter plot as these three bands have the highest eigenvalue among the six bands. Four endmembers were selected in this study, including high albedo, low albedo, soil, and vegetation. The water part had to be masked first in order to achieve an accurate result. The combination of high albedo and low albedo was the impervious surface area that was used to calculate the impervious surface estimation in the study. The fraction of impervious surface areas in 1995, 2004, and 2015 will be compared. 


\subsection{Accuracy Assessment}

The correlation coefficient $\left(R^{2}\right)$, the root mean square error (RMSE), and the mean absolute error $(M A E)$ were used to assess the accuracy of the impervious surface estimation [3]. The equations for RMSE and MAE are written as below:

$$
\begin{aligned}
& \text { RMSE }=\sqrt{\frac{\sum_{i=1}^{N}\left(X_{i}-Y_{i}\right)^{2}}{N}} \\
& M A E=\frac{1}{N} \sum_{i=1}^{N}\left|X_{i}-Y_{i}\right|
\end{aligned}
$$

where $X_{i}$ is the estimated impervious surface fraction of sample $i ; Y_{i}$ is the actual impervious surface fraction; and $N$ is the number of selected samples [4]. The lower are the RMSE and MAE values, the higher is the accuracy of the estimation of impervious surface. The higher value of $R^{2}$ implied a strong linear relationship of the samples, in which the result was reliable as well [35-37].

\section{Results and Discussion}

\subsection{Minimum Noise Fraction (MNF)}

Figure 3a-f and Table 2 show that the eigenvalue of MNF 1, MNF 2, MNF 3, MNF 4, MNF 5, and MNF 6 were 29.99, 9.49, 4.22, 3.15, 2.45, and 1.53, respectively. The contribution rates of MNF 1, MNF 2, MNF 3, MNF 4, MNF 5, and MNF 6 were 59.01\%, 18.67\%, 8.30\%, 6.20\%, 4.82\% and 3.01\%, respectively. The eigenvalue of MNF 1 was the largest, which demonstrated the highest data dimensionality, and the eigenvalues of the six MNFs were greater than 1. MNF 1 showed the clearest demonstration of the topologic characteristic, as its contribution rate was the highest. MNF 2 probably indicated high albedo and low albedo. MNF 3 demonstrated soil and vegetation. Thus, MNF 1, MNF 2, and MNF 3 were applied in the 2D scatter plot to select the endmembers.

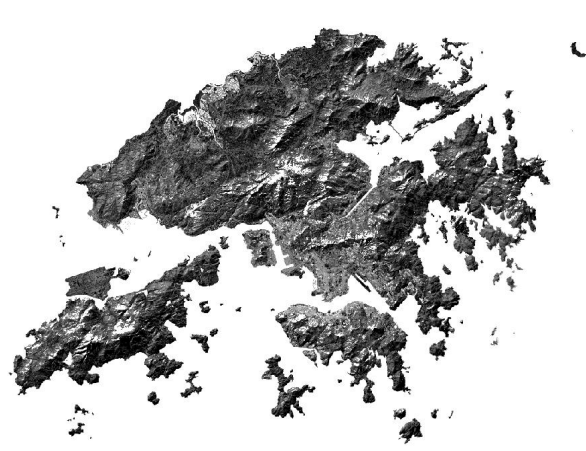

(a)

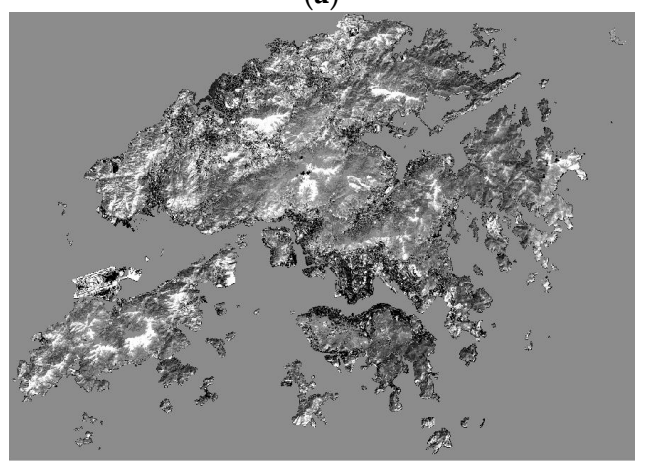

(c)

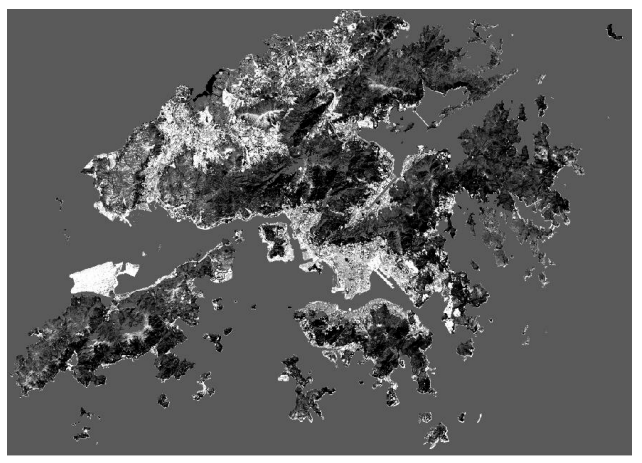

(b)

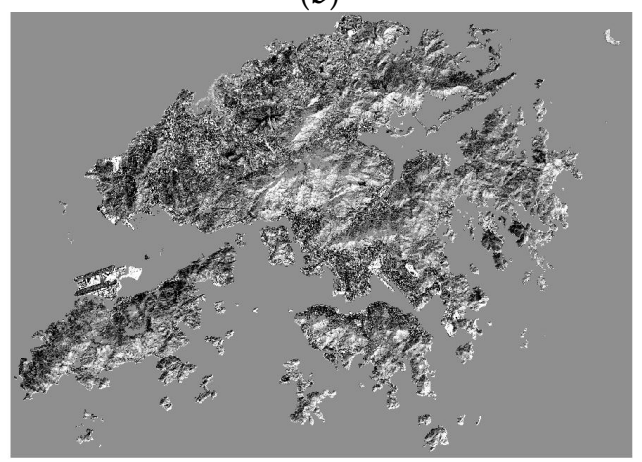

(d)

Figure 3. Cont. 


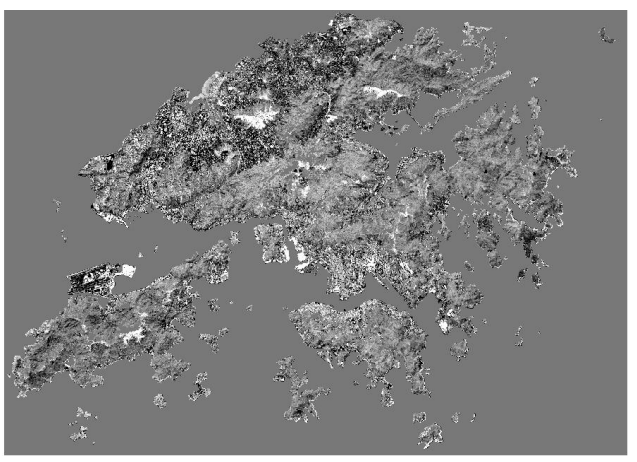

(e)

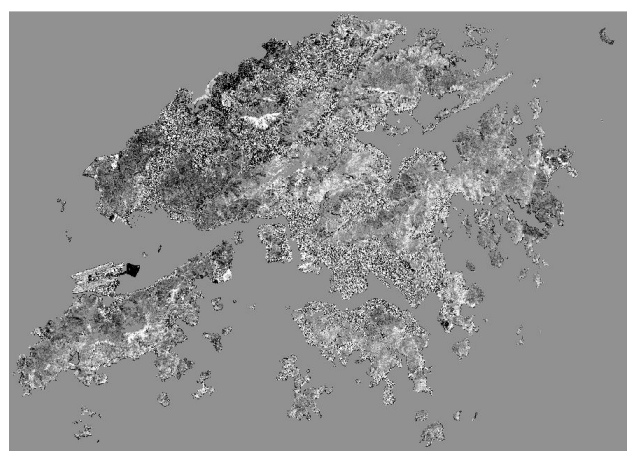

(f)

Figure 3. (a) MNF (minimum noise fraction) Band 1; (b) MNF Band 2; (c) MNF Band 3; (d) MNF Band 4; (e) MNF Band 5; and (f) MNF Band 6.

Table 2. Eigenvalue and contribution rate of MNF of six bands for 2015.

\begin{tabular}{ccccccc}
\hline & MNF 1 & MNF 2 & MNF 3 & MNF 4 & MNF 5 & MNF 6 \\
\hline Eigenvalue & 29.99 & 9.49 & 4.22 & 3.15 & 2.45 & 1.53 \\
Contribution rate & $59.01 \%$ & $18.67 \%$ & $8.30 \%$ & $6.20 \%$ & $4.82 \%$ & $3.01 \%$ \\
\hline
\end{tabular}

\subsection{Endmember Selection}

The endmember selection in the study was based on the V-H-L-S model, as there were four endmembers: high albedo, vegetation, low albedo, and soil. The water area had to be masked to attain a more accurate result. Figure $4 \mathrm{a}-\mathrm{c}$ shows the 2D scatter plots of MNFs for MNF 1-MNF 2, MNF 1-MNF 3, and MNF 2-MNF 3, which were used to select the endmember. The angle of the linear triangle is formed by three endmembers, indicating the specific endmembers. The high albedo land type had a high reflectance as high albedo contained some buildings with special materials, roads, and different infrastructures. The low albedo land type mainly contained residential buildings, shade, wet soil, and water. The vegetation included trees (or shrubs) and grass (or crops). The land type of soil was the dry soil and bare sand or rock. In the 2D scatter plot of MNF 1-MNF 2, high albedo, low albedo, and vegetation were found. In the 2D scatter plot of MNF 1-MNF 3, high albedo, low albedo, and soil were found. In the 2D scatter plot MNF 2-MNF 3, low albedo, vegetation, and soil were found. Some dispersed black points around the linear triangle represented noise.

Figure 5 shows the reflectance of the four endmembers. The true color of the Landsat 8 image applied for RGB was Band 4-Band 3-Band 2. The high albedo had the highest reflectance for Bands 1-5, as these areas had a wide variety of materials and facilities. The soil had a slightly higher reflectance than low albedo and the vegetation for Bands 1-4. The vegetation had the lowest reflectance as the forest absorbed the most radiation and reflected less to the remote sensor. The soil and vegetation had a higher reflectance than high albedo and low albedo in Band 5. These four endmembers were selected for the linear spectral un-mixing analysis. Figure 6 shows an example of the land area of Hong Kong in 2015 after the water area was masked in the study. 


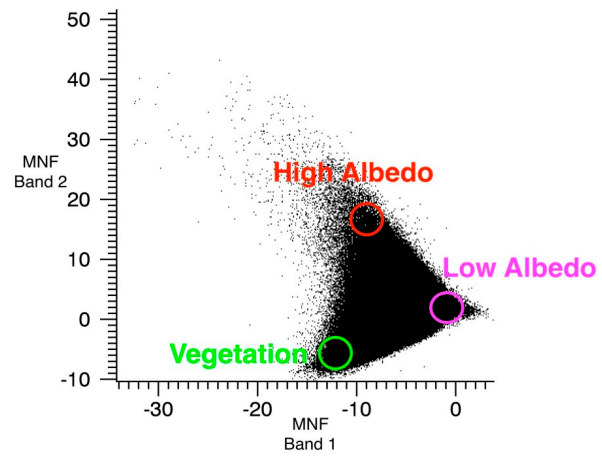

(a)

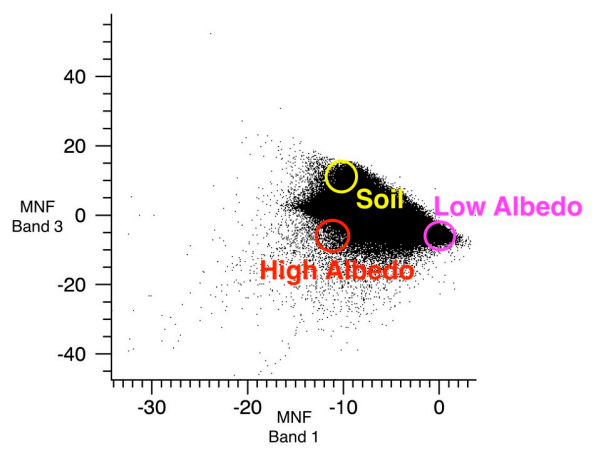

(b)

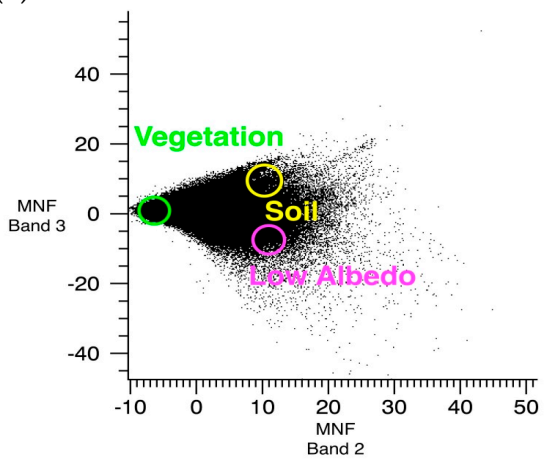

(c)

Figure 4. (a) 2D scatter plot of MNF 1-MNF 2; (b) 2D scatter plot of MNF 1-MNF 3; and (c) 2D scatter plot of MNF 2-MNF 3.

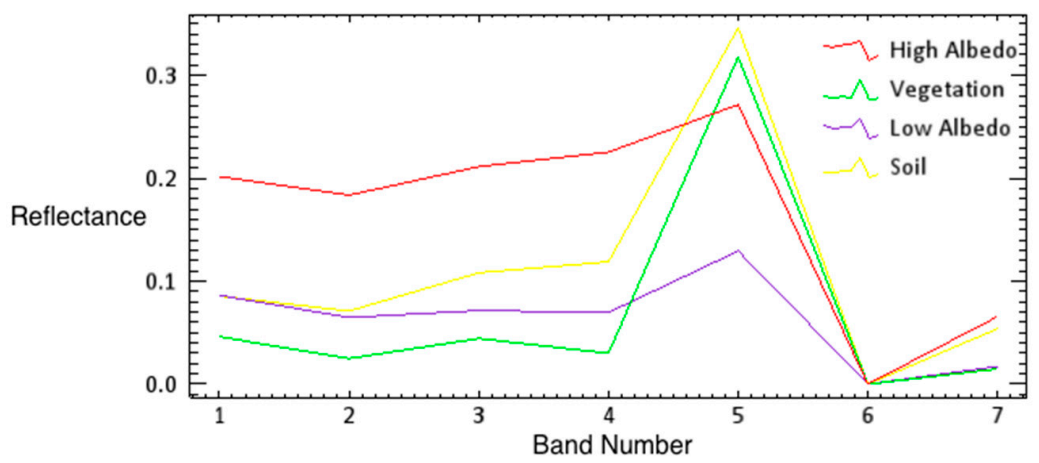

Figure 5. The reflectance of the four endmembers.

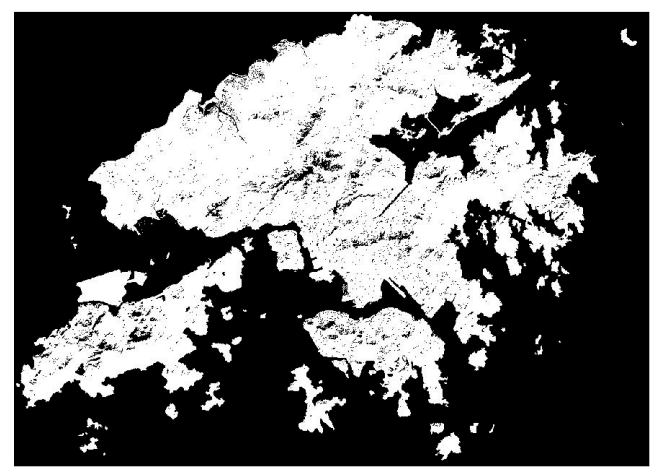

Figure 6. An example of the land area of Hong Kong in 2015 after the water was masked. 


\subsection{Linear Spectral Un-Mixing}

The linear spectral un-mixing analysis [38] provided five types of layers: the reflectance values of the high albedo, low albedo, vegetation, soil, and root mean square (RMS) [39,40]. The fraction composition of each endmember was shown regarding their specific features. The image of linear spectral un-mixing of high albedo was the bright area with some special infrastructures. The most distinctive area was the Hong Kong international airport in Chek Lap Kok. The image of linear spectral un-mixing of low albedo was the area with a high density of residential buildings in the urban area in each district. The image of linear spectral un-mixing of soil was the area with the bare soil and sands or rocks. The image of linear spectral un-mixing of vegetation was the area with mountainous trees (or shrubs) and grass (or crops).

As shown in Table 3, according to the statistics for the linear spectral un-mixing in 1995, the mean proportion rates of high albedo, low albedo, soil, and vegetation were $13.81 \%, 23.80 \%, 19.77 \%$, and $42.62 \%$, respectively. According to the statistics for the linear spectral un-mixing in 2004, the mean proportion rates of high albedo, low albedo, soil, and vegetation were $12.46 \%, 25.48 \%, 15.69 \%$, and $46.26 \%$, respectively. According to the statistics for the linear spectral un-mixing in 2015, the mean proportion rates of high albedo, low albedo, soil, and vegetation were $13.80 \%, 24.77 \%, 16.06 \%$, and $45.36 \%$, respectively. Figure 7 shows an example of the linear spectral un-mixing results in 2015.

Table 3. Fraction of each endmember in 1995, 2004 and 2015.

\begin{tabular}{ccccc}
\hline & High Albedo & Low Albedo & Soil & Vegetation \\
\hline 1995 & $13.81 \%$ & $23.80 \%$ & $19.77 \%$ & $42.62 \%$ \\
2004 & $12.46 \%$ & $25.48 \%$ & $15.69 \%$ & $46.26 \%$ \\
2015 & $13.80 \%$ & $24.77 \%$ & $16.60 \%$ & $45.36 \%$ \\
\hline
\end{tabular}

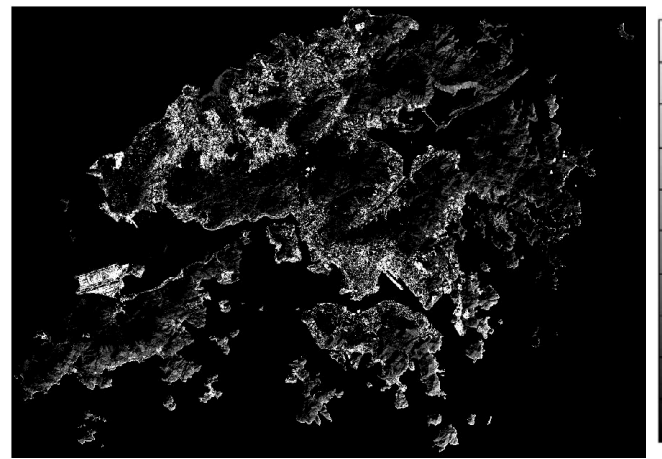

(a)

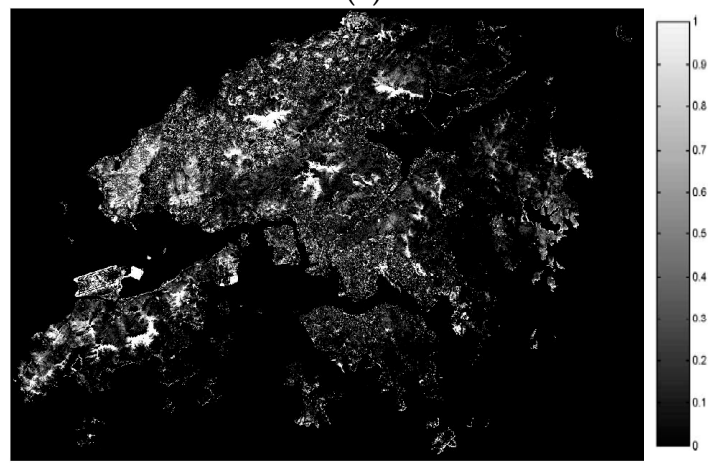

(c)

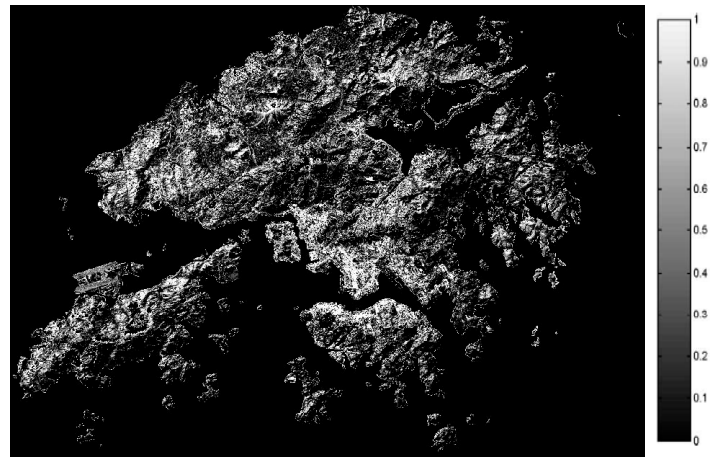

(b)

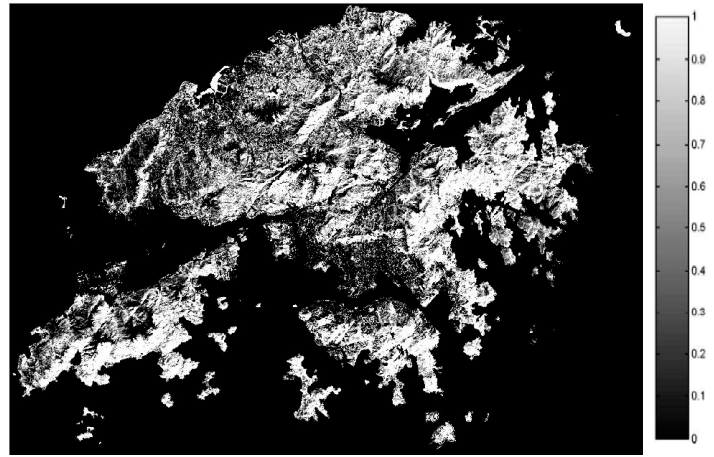

(d)

Figure 7. (a) Linear spectral un-mixing of high albedo of 2015; (b) linear spectral un-mixing of low albedo of 2015; (c) linear spectral un-mixing of soil of 2015; and (d) linear spectral un-mixing of vegetation of 2015 . 


\subsection{Impervious Surface Estimation}

The impervious surface estimation was obtained from the combination of two endmembers: high albedo and low albedo. The variability of brightness of the impervious surface fraction image demonstrates the amount of the impervious surface area and the spatial distribution. Brighter areas indicate higher abundance of impervious surface fraction. In the impervious surface fraction of 1995, the abundance of impervious surface fraction distributed in the center of Hong Kong (i.e., Tsim Sha Tsui, Mong Kok, Tsuen Wan, Central, Wan Chai, and Causeway Bay) and the Chek Lap Kok was the highest. As Central is the commercial business district: Tsim Sha Tsui, Causeway Bay, and Mong Kok include many business-purpose buildings; and Chek Lap Kok had an airport construction project, the abundance rate in these areas could therefore reach nearly 95\%. There were many high-density residential buildings in these areas, in which the abundance rate was above $70 \%$. The area in western Hong Kong, New Territories, which had a relatively low abundance rate, was about $40 \%$ to $60 \%$. Residential buildings were the main portion of buildings developed in the New Territories. The abundance rates of vegetation and soil were about $20 \%$ or below.

Figure 8a-c shows the impervious surface proportions of 1995, 2004, and 2015 were 37.61\%, 37.94\% and $38.57 \%$, respectively. The proportion of impervious surface area of Hong Kong increased over each decade. The rate of increase was $0.33 \%$ from 1995 to 2004 and the increasing rate was $0.63 \%$ from 2004 to 2015. The overall rate of increase over this twenty-year period from 1995 to 2015 was $0.96 \%$. The impervious surface area included the urban areas of each district, such as Mong Kok, Causeway Bay, Tsim Sha Tsui, Yuen Long, Sha Tin, and Chek Lap Kok.

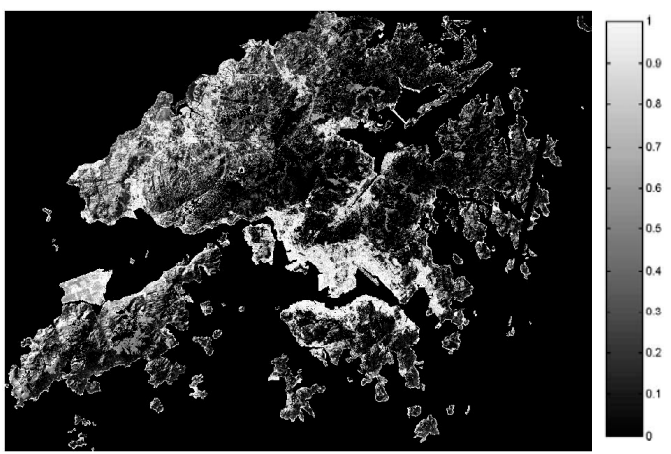

(a)

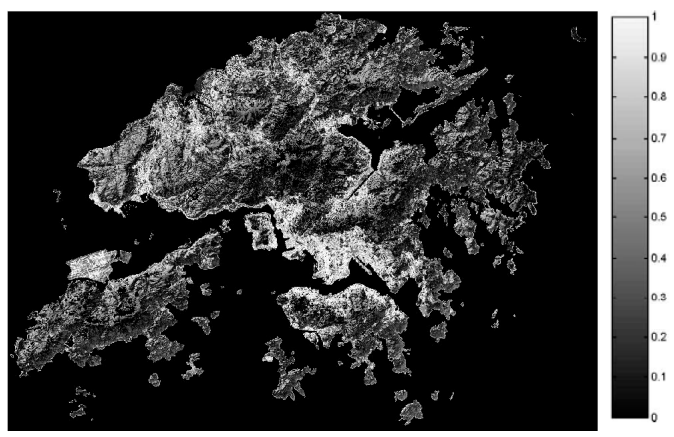

(c)

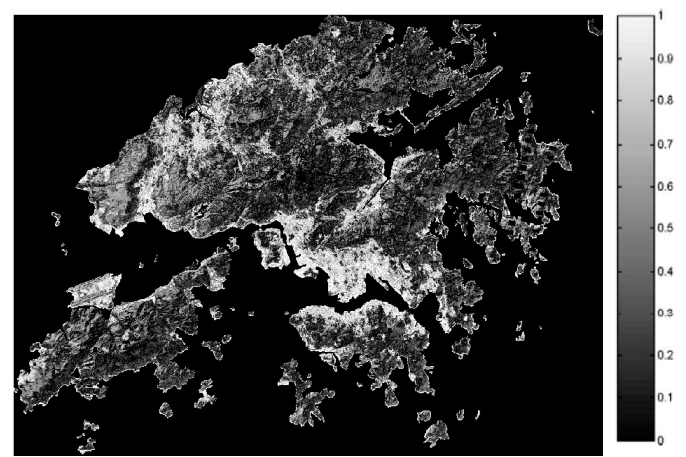

(b)

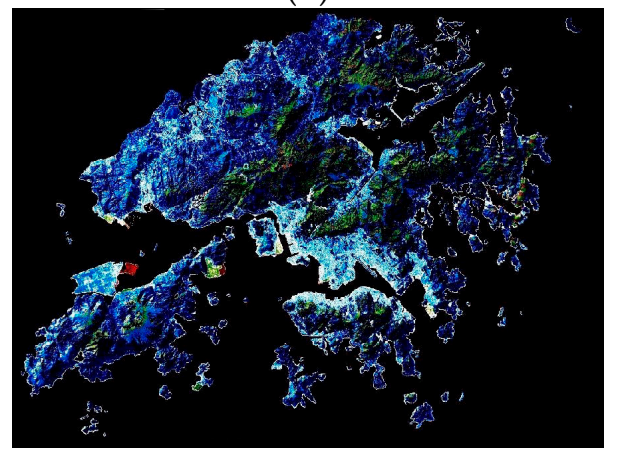

(d)

Figure 8. (a) Impervious surface fraction of 1995; (b) impervious surface fraction of 2004; (c) impervious surface fraction of 2015; and (d) composite of 1995, 2004, 2015.

Figure $8 \mathrm{~d}$ is composed the impervious surface of 1995, 2004, and 2015, in which blue color represented the impervious surface of 1995, green color represented the impervious surface of 2004, and red color represented the impervious surface of 2015. The increased impervious surface area was caused by the reclamations. The increase of the reclaimed areas from 1995 to 2004 was the 
southern Tuen Mun (Figure 9a) and Hong Kong Disneyland Resort (Figure 9b). The increase of the reclaimed area from 2004 to 2015 was the northeast of Chek Lap Kok, including the seawall of the Hong Kong-Zhuhai-Macau Bridge (Figure 9c).

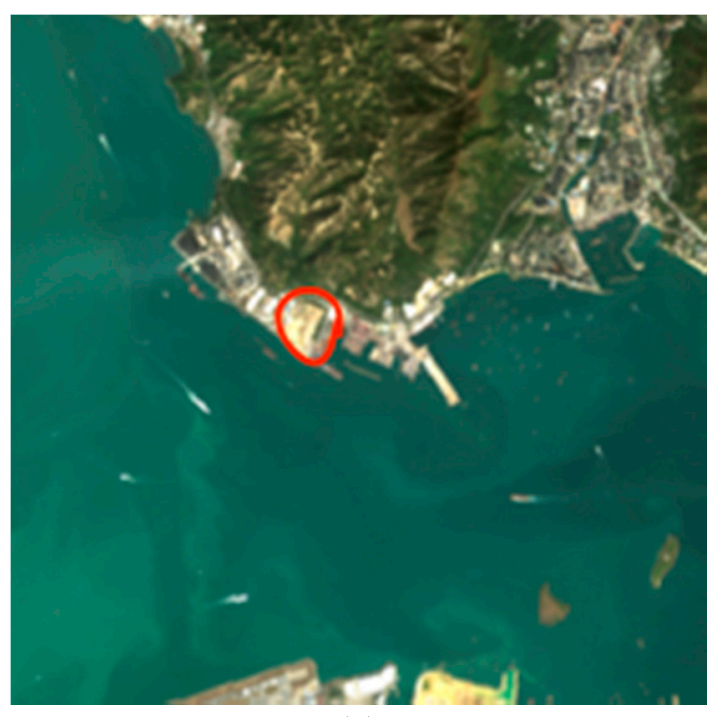

(a)

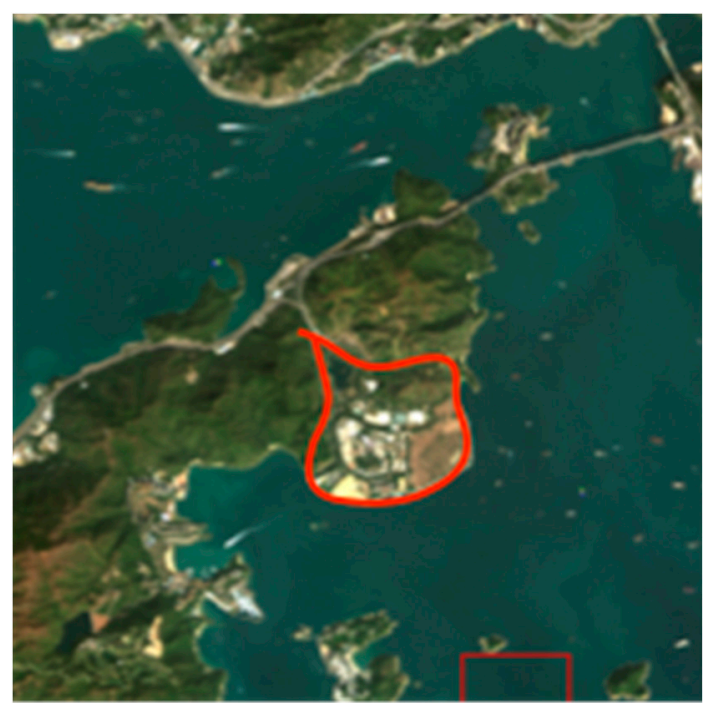

(b)

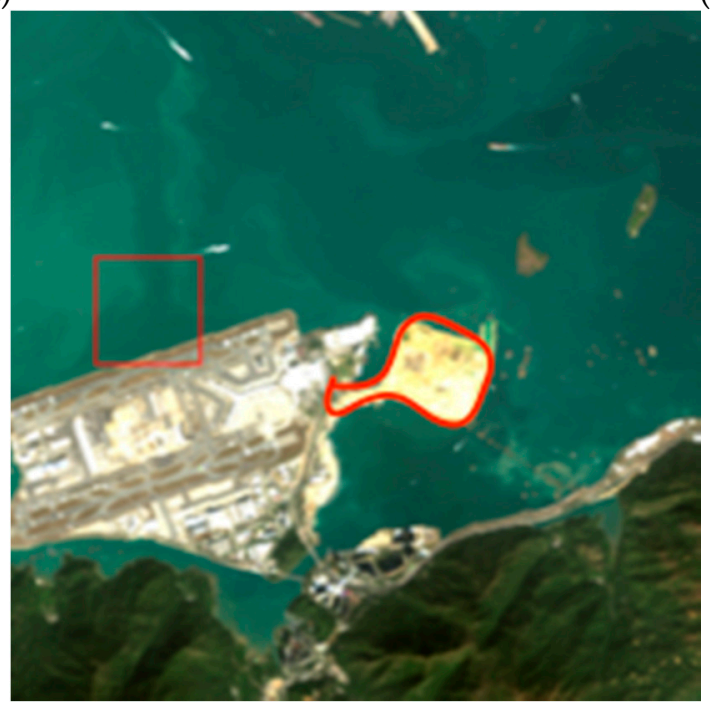

(c)

Figure 9. (a) The southern of Tuen Mun $\left(22^{\circ} 21^{\prime} \mathrm{N}, 113^{\circ} 55^{\prime} \mathrm{E}\right)$; (b) Hong Kong Disneyland Resort $\left(22^{\circ} 18^{\prime} \mathrm{N}, 114^{\circ} 04^{\prime} \mathrm{E}\right)$; and (c) the Hong Kong-Zhuhai-Macau Bridge $\left(22^{\circ} 19^{\prime} \mathrm{N}, 113^{\circ} 57^{\prime} \mathrm{E}\right)$.

\subsection{Accuracy Assessment}

The root mean square (RMS) was used to assess accuracy result as shown in Figure 10, which is the fifth layer of the result of linear spectral un-mixing analysis. The root mean square should be within 0.02 for an acceptable result. For example, the minimum value, maximum value and mean value of the RMS in 1995 are $0.00,0.21$, and 0.00093 , respectively. The minimum value, maximum value and mean value of the RMS in 2004 were $0.00,0.28$, and 0.0021 , respectively. The minimum value, maximum value and mean value of the RMS in 2015 were $0.00,0.31$ and 0.0016 , respectively. Most pixels were less than the acceptance standard 0.02; thus, the accuracy of the study is high and the results are reliable. 


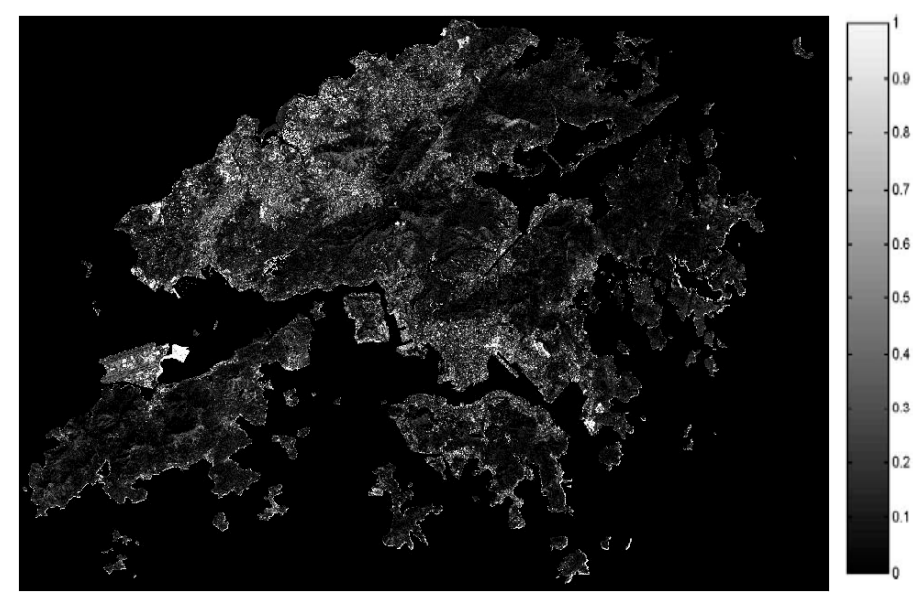

Figure 10. RMS (root mean square) result of 2015.

The RMS value was high in the region at $0-0.001220$ in $1995,0-0.001126$ in 2004 , and $0-0.00805$ in 2015. The high RMS value was mainly located in between the low albedo and vegetation regions because Hong Kong has many mountains that have a shading effect on other vegetation areas. The shading effect would be classified as low albedo. The land cover type of high albedo was complex, leading to a high degree of RMS. Thus, complicated land types in those areas affected the accuracy of the classification of the endmembers.

In order to validate the results, Google Earth images were used to assess the accuracy of the result regarding impervious surface estimation from Landsat TM images. A random sampling of 100 numbers of $3 \times 3$ pixels of Landsat TM data was chosen for comparison with the equivalent location of the photograph in Google Earth. The actual fraction of endmembers could be digitized through the examples of Google Earth photographs (Table 4).

Table 5 shows the results of the regression model for the actual value and sample value of the impervious surface fraction estimation [41,42] for 1995, 2004, and 2015. Figures 11-13 show that the value of $R^{2}$ of the Landsat TM image in 1995 was 0.98 ; the value of $R^{2}$ of the Landsat TM image in 2004 was 0.92 ; and the value of $R^{2}$ of the Landsat TM image in 2015 was 0.98 . The values of $R^{2}$ implied in the Landsat TM images were acceptable. The residual analysis of the impervious surface estimation for 1995, 2004 and 2015 was calculated below as well. The values of RMSE (Equation (3)) and MAE (Equation (4)) from 1995 were 3.29\% and 2.16\%, respectively. The values of RMSE (Equation (3)) and MAE (Equation (4)) from 2004 were $5.60 \%$ and $4.89 \%$, respectively. The values of RMSE (Equation (3)) and MAE (Equation (4)) from 2015 were $0.98 \%$ and $0.79 \%$, respectively. The range of residual analysis was between 0.2 and -0.2 , as shown in Figures $11 b, 12 b$ and $13 b$. The fractions of samples with more than $70 \%$ contained the highest amount of error when compared with the actual fraction as most of the samples were underestimated. Some of the sample fraction of soil and vegetation were overestimated, which should be lower than 0.25 of the abundance rate. Because of the shade covering on the vegetation and soil in reality, those parts were defined as the low albedo fraction through the endmember classification.

High correlation coefficients, low RMSE, and low MAE were obtained from the three data sets in 1995, 2004, and 2015; thus, the accuracy of the results of the three data sets was high; the charts for the regression model and residual analysis were plotted as shown in Figures 11-13. 
Table 4. Random Samples of Landsat TM images and Google Earth photographs.

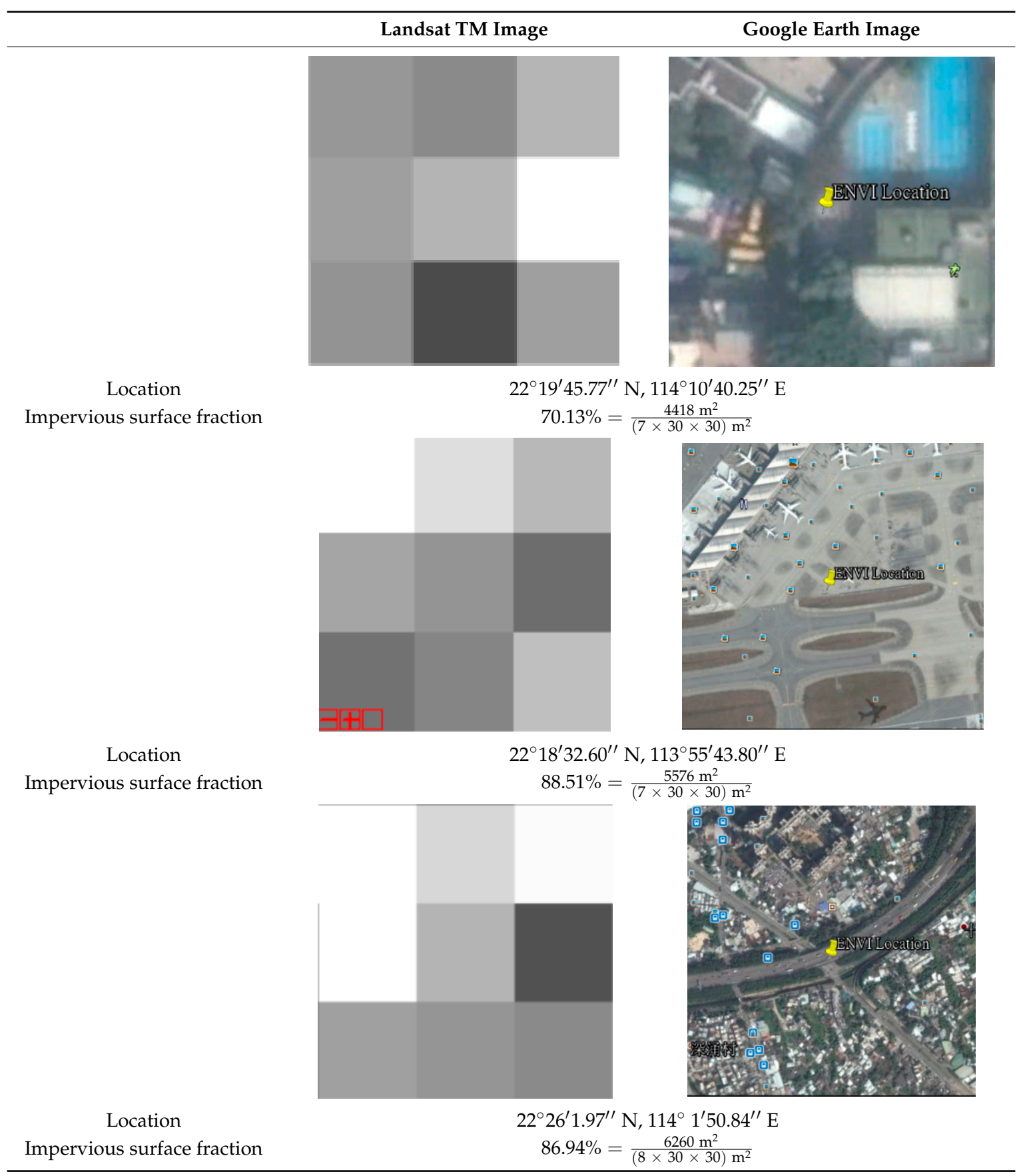

Table 5. The value of $R^{2}$ of the Landsat TM image in 1995, 2004, and 2015.

\begin{tabular}{llll}
\hline & $\mathbf{1 9 9 5}$ & $\mathbf{2 0 0 4}$ & $\mathbf{2 0 1 5}$ \\
\hline Value of $R^{2}$ & 0.98 & 0.92 & 0.98 \\
\hline
\end{tabular}




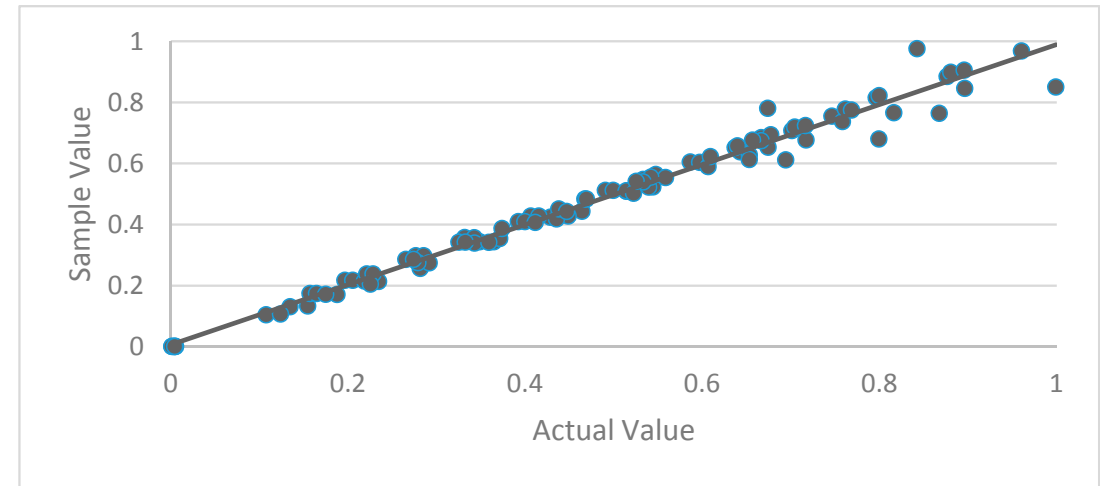

(a)

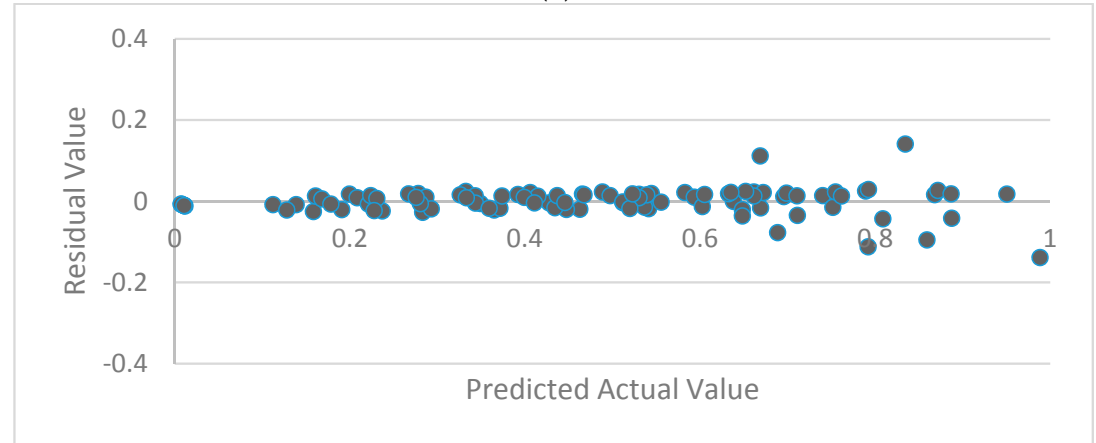

(b)

Figure 11. (a) Regression results in 1995, $y=0.9828 x+0.0066, R^{2}=0.98(n=100)$; and (b) residual results in 1995, RMSE (root mean square error): $3.29 \%(n=100)$, MAE (mean absolute error): $2.16 \%$ $(n=100)$.

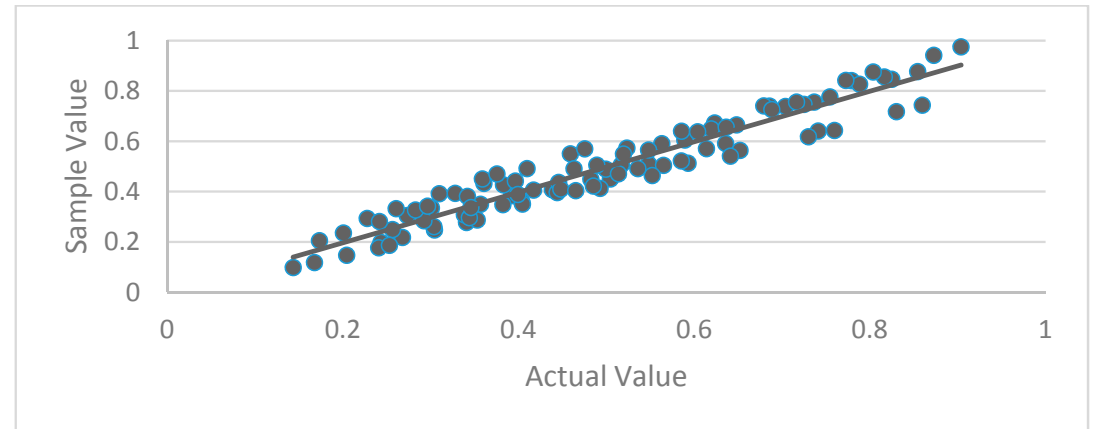

(a)

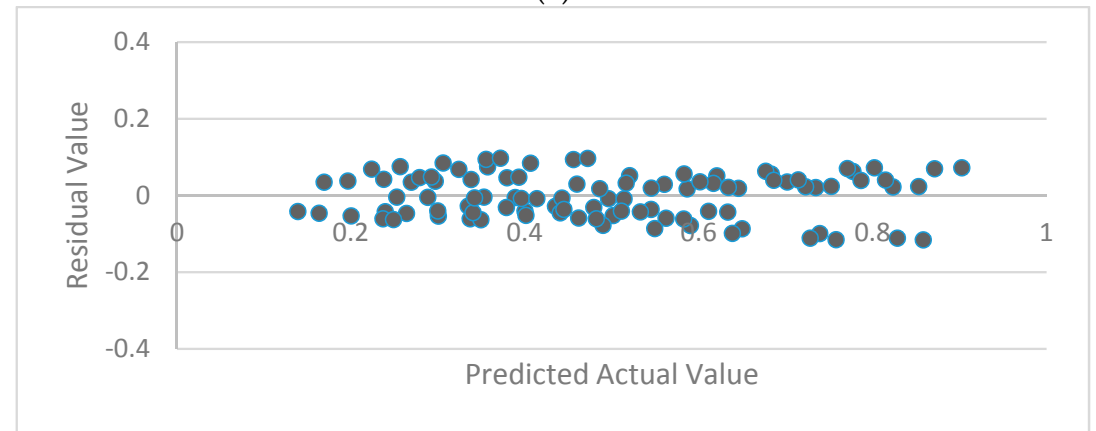

(b)

Figure 12. (a) Regression results in 2004, $y=1.004 x-0.0049, R^{2}=0.92(n=100)$; and (b) residual results in 2004, RMSE: $5.60 \%(n=100)$, MAE: $4.89 \%(n=100)$. 


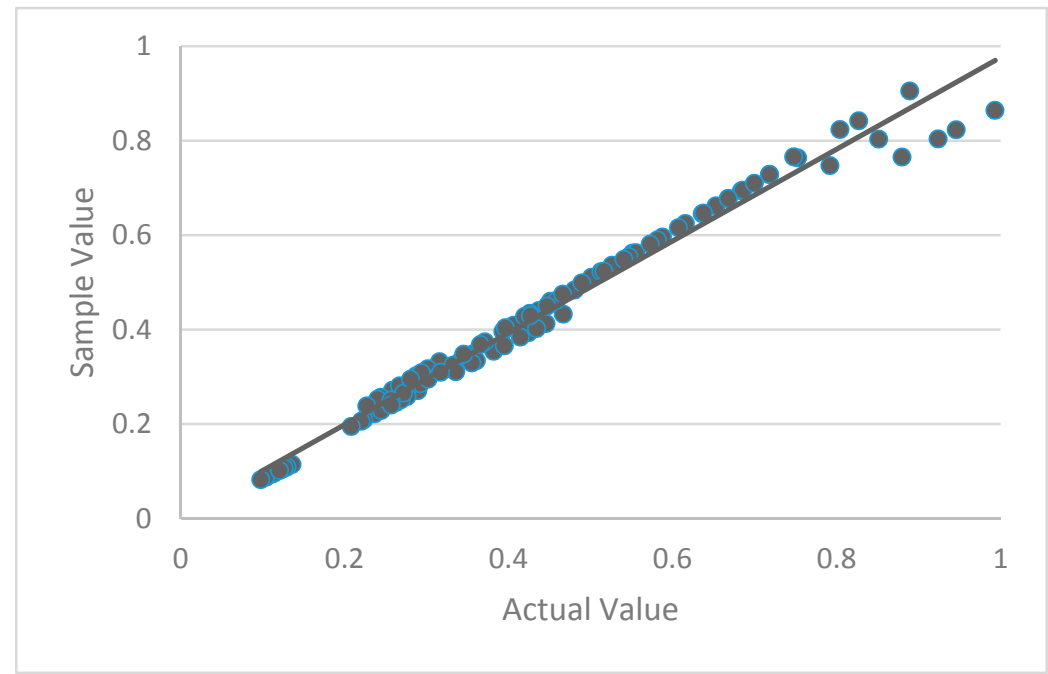

(a)

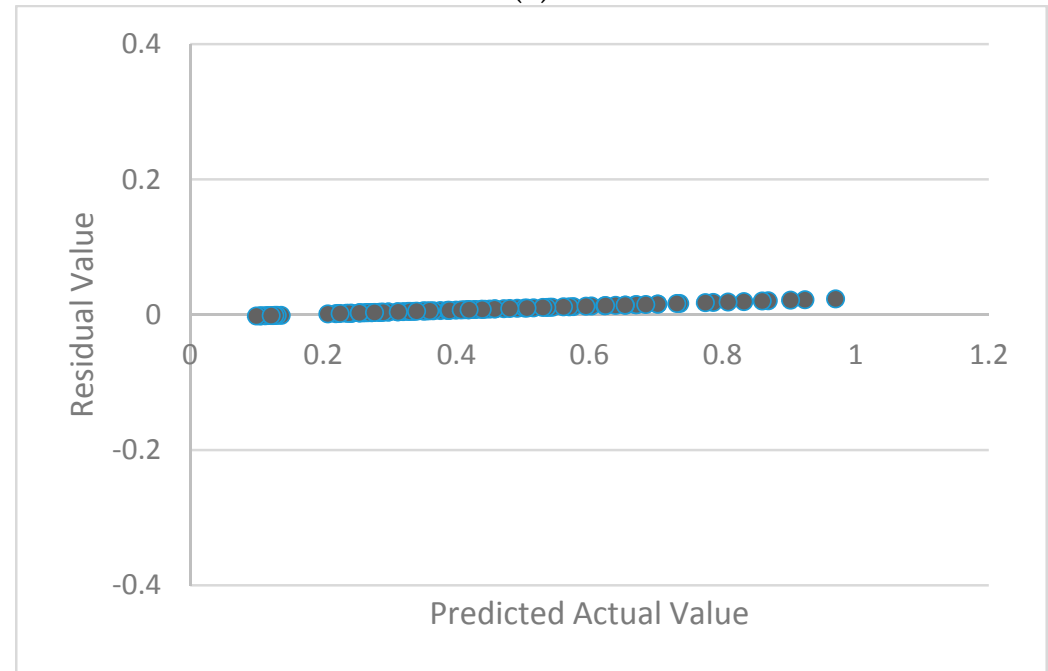

(b)

Figure 13. (a) Regression results in 2015, $y=0.9717 x+0.0047, R^{2}=0.98(n=100)$; and (b) residual results in 2004, $\operatorname{RMSE}=0.979 \%(n=100)$, MAE $=0.792 \%(n=100)$.

\section{Analysis and Discussion}

\subsection{Changes Related to Land Use and Land Cover}

Figure 14 shows the change trend related to the abundance of high albedo, vegetation, low albedo, and soil in 1995, 2004, and 2015. The fraction of high albedo decreased from $13.81 \%$ in 1995 to $12.46 \%$ in 2004 and increased to $13.80 \%$ in 2015 (see Table 3). The decreasing rate of high albedo from 1995 to 2004 was $1.35 \%$, and the increasing rate from 2004 to 2015 was $1.34 \%$. The fraction of vegetation increased from $42.62 \%$ in 1995 to $46.26 \%$ in 2004 and decreased to $45.36 \%$ in 2015 (see Table 3). The increasing rate of vegetation from 1995 to 2004 was $3.54 \%$, and the decreasing rate from 2004 to 2015 was $0.90 \%$. The fraction of low albedo increased from $23.80 \%$ in 1995 to $25.48 \%$ in 2004 and decreased to $24.77 \%$ in 2015 (see Table 3). The increasing rate of low albedo from 1995 to 2004 was $1.68 \%$, and the decreasing rate from 2004 to 2015 was $0.71 \%$. The fraction of soil decreased from $19.77 \%$ in 1995 to $15.69 \%$ in 2004 and increased to $16.06 \%$ in 2015 (see Table 3). The decreasing rate of soil from 1995 to 2004 was $4.08 \%$, and the increasing rate from 2004 to 2015 was $0.37 \%$. 
The overall change rate of each endmember from 1995 to 2015 was calculated. There was a decrease of $0.01 \%$ in the high albedo fraction. There was an increase of $2.74 \%$ in the vegetation fraction. There was an increase of $0.97 \%$ in the low albedo fraction. There was a decrease of $3.71 \%$ in soil.

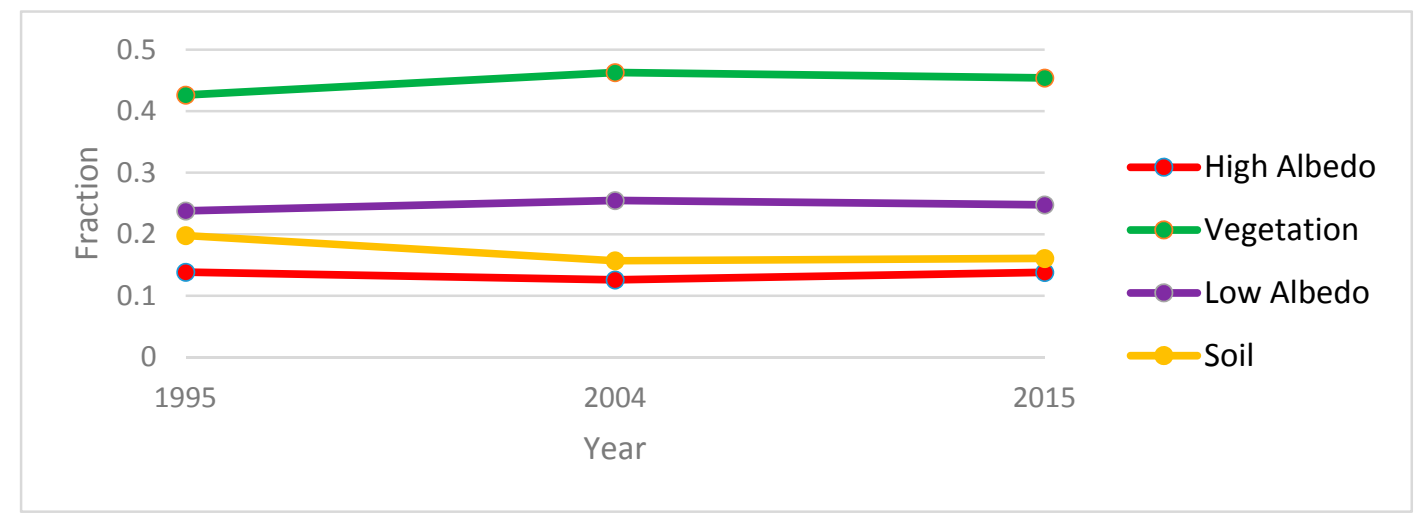

Figure 14. The change rate of fraction of each endmember.

Figure 15 shows the change trend regarding the fraction of impervious surface was calculated. The fraction of impervious surface increased from 37.61\% in 1995 to $37.94 \%$ in 2004 and further increased to $38.57 \%$ in 2015 . The increasing rate of the impervious surface area of Hong Kong was $0.33 \%$ from 1995 to 2004 and $0.63 \%$ from 2004 to 2015 . The overall increase of the fraction impervious surface was $0.96 \%$.

Figure 16 shows the change trend of fraction for land, sea, and impervious surface was calculated, in which the total area of the study area was composed of land and sea areas as $2755 \mathrm{~km}^{2}$ [29]. Table 6 shows the percentage of fraction of land as 35.68\% in 1995, 40.15\% in 2004, and $45.68 \%$ in 2015. The percentage of the fraction of sea was $64.32 \%$ in $1995,59.85 \%$ in 2004 , and 54.32\% in 2015. The percentage of the fraction of impervious surface calculated with the land area as a basis was $37.60 \%$ in 1995, 37.94\% in 2004, and 38.56\% in 2015. The rate of increase of land area from 1995 to 2015 was $10.00 \%$. The rate of decrease of sea area from 1995 to 2015 was $10.00 \%$. The increasing rate of impervious surface area from 1995 to 2015 was $0.96 \%$.

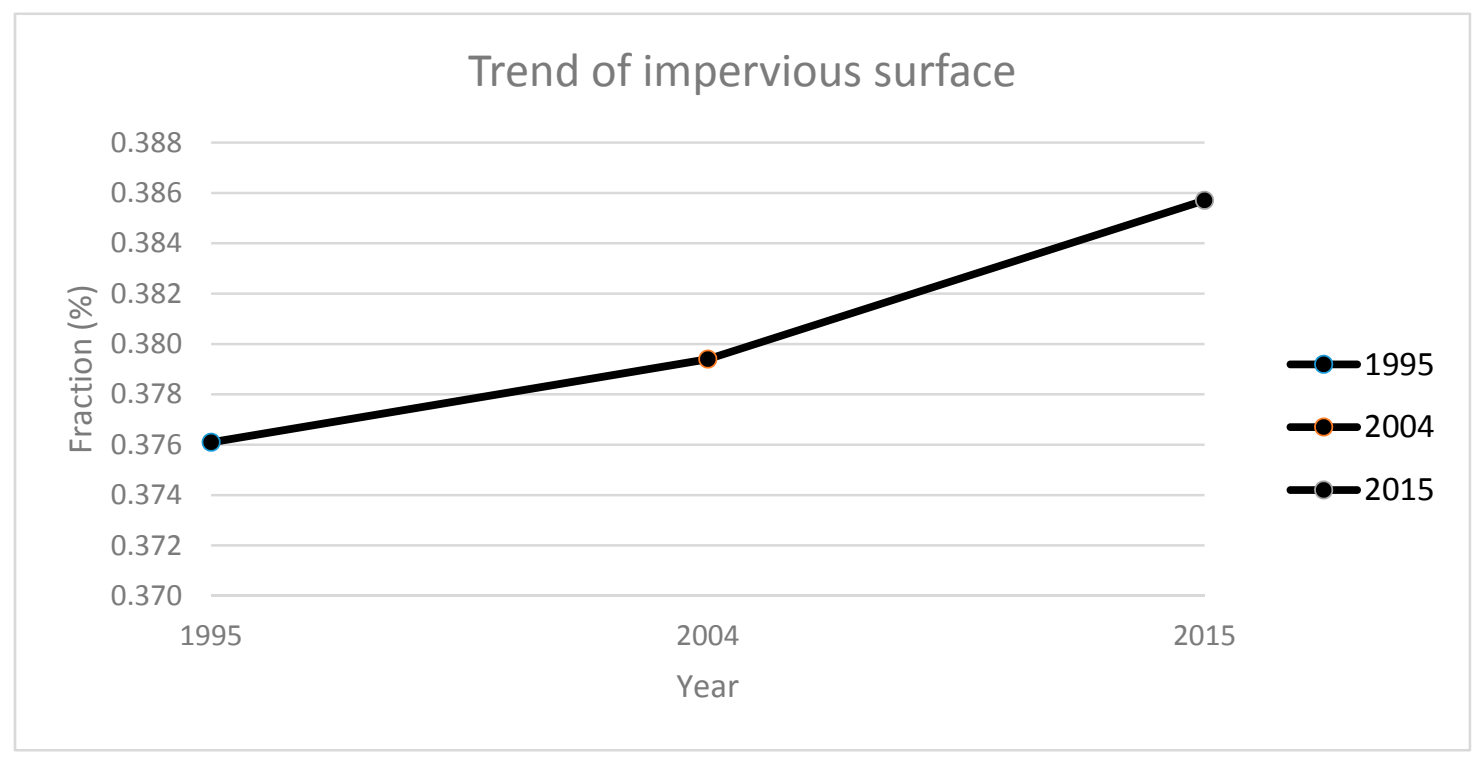

Figure 15. The change rate of impervious surface. 


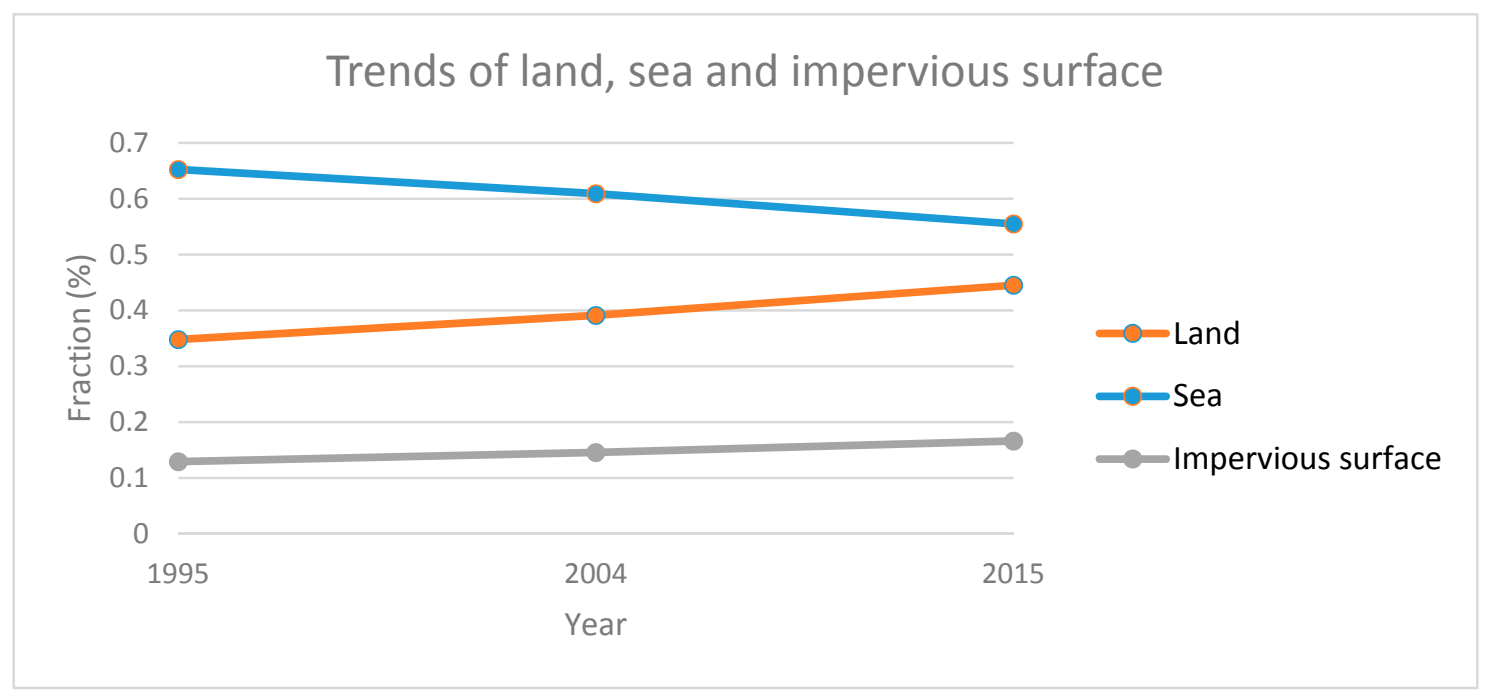

Figure 16. The change rate of land, sea, and impervious surface.

Table 6. Percentage and area of land, sea, and impervious surface in each year.

\begin{tabular}{cccc}
\hline Type/Year & $\mathbf{1 9 9 5}$ & $\mathbf{2 0 0 4}$ & $\mathbf{2 0 1 5}$ \\
\hline Land & $35.68 \%\left(982.99 \mathrm{~km}^{2}\right)$ & $40.15 \%\left(1106.01 \mathrm{~km}^{2}\right)$ & $45.68 \%\left(1258.43 \mathrm{~km}^{2}\right)$ \\
Sea & $64.32 \%\left(1772.01 \mathrm{~km}^{2}\right)$ & $59.85 \%\left(1648.99 \mathrm{~km}^{2}\right)$ & $54.32 \%\left(1496.57 \mathrm{~km}^{2}\right)$ \\
Impervious surface & $37.60 \%\left(369.61 \mathrm{~km}^{2}\right)$ & $37.94 \%\left(419.67 \mathrm{~km}^{2}\right)$ & $38.56 \%\left(485.27 \mathrm{~km}^{2}\right)$ \\
\hline
\end{tabular}

Table 6 also shows the area of land, sea, and impervious surface in 1995, 2004, and 2015. The areas of land in 1995, 2004, and 2015 were $982.99 \mathrm{~km}^{2}, 1106.01 \mathrm{~km}^{2}$, and $1258.43 \mathrm{~km}^{2}$, respectively. The areas of sea in 1995, 2004, and 2015 were $1772.01 \mathrm{~km}^{2}, 1648.99 \mathrm{~km}^{2}$ and $1496.57 \mathrm{~km}^{2}$, respectively. The areas of impervious surface in 1995, 2004 and 2015 were $369.61 \mathrm{~km}^{2}, 419.67 \mathrm{~km}^{2}$, and $485.27 \mathrm{~km}^{2}$, respectively.

\subsection{Effect of the Change of Land, Sea, and Impervious Surface Area}

Due to the policy regarding conservation of country parks in Hong Kong, reclamation is the only way to expand the land area. The Praya Reclamation Scheme, the earliest reclamation project in Hong Kong, was carried out in the 1860s, and the reclamation projects that followed have been carried out up to the present time. Land was added at the southern end of Tuen Mun in the impervious surface fraction estimation for 2004. There was also land added to the northeast of Chek Lap Kok, which was the seawall for the Hong Kong-Zhuhai-Macau Bridge, in the impervious surface fraction estimation for 2015. Therefore, the land area increased from 1995 to 2015 as well as the impervious surface area. Because the study area is composed of land and sea in a fixed area, the sea area had an inverse relationship with the land area. Thus, the sea area decreased as the land area increased. As the area of reclamation was used to develop residential buildings and infrastructures, the impervious surface increased. However, Hong Kong has a set of policies to protect the high-ecological-value country parks. The increase in vegetation was probably due to the re-colonization of vegetation (2015) in the areas first occupied by bare soil. The decrease in soil was probably was replaced by vegetation and/or low albedo.

\subsection{Factors in the Discrepancy between Actual and Estimated Fraction}

A Greening Campaign was held in Hong Kong in 2010. Therefore, many trees and shrubs have been planted in residential areas. Furthermore, the rooftops of some commercial buildings and residential buildings were planted with different shrubs or trees. These areas, therefore, would probably be considered as vegetation when conducting an impervious surface estimation. The uncorrected 
classification between urban area and vegetation could lower the amount of impervious surface area; thus, the result may be affected.

Due to the hilly characteristic of Hong Kong, the huge mountains generated some shade over their surrounding areas. The shade was classified as the low albedo area. The estimation of the impervious surface fraction could be affected by the shading effect. In order to minimize the shading effect, manual classification on the pixels of the shaded area was carried out to change it from low albedo to vegetation.

\subsection{Challenges for Hong Kong}

As the rate of population growth remains high in Hong Kong (Figure 17), more residential buildings and infrastructures will have to be built to meet the basic needs of citizens. The total population is about 7.40 million now, and the population growth rate is anticipated to increase in the coming years. From the chart showing population growth [5], there will be 8.10 million of population in 2034 (Figure 17). The concerning for Hong Kong is whether there is sufficient flat land for further development. Because of limited land available for use in Hong Kong, there are many pencil-thin buildings now and the density is extremely high. High density development in Hong Kong is accelerating urbanization, which in all probability is resulting in an urban heat island [43]. The high temperatures in urban areas may lead to various health problems.

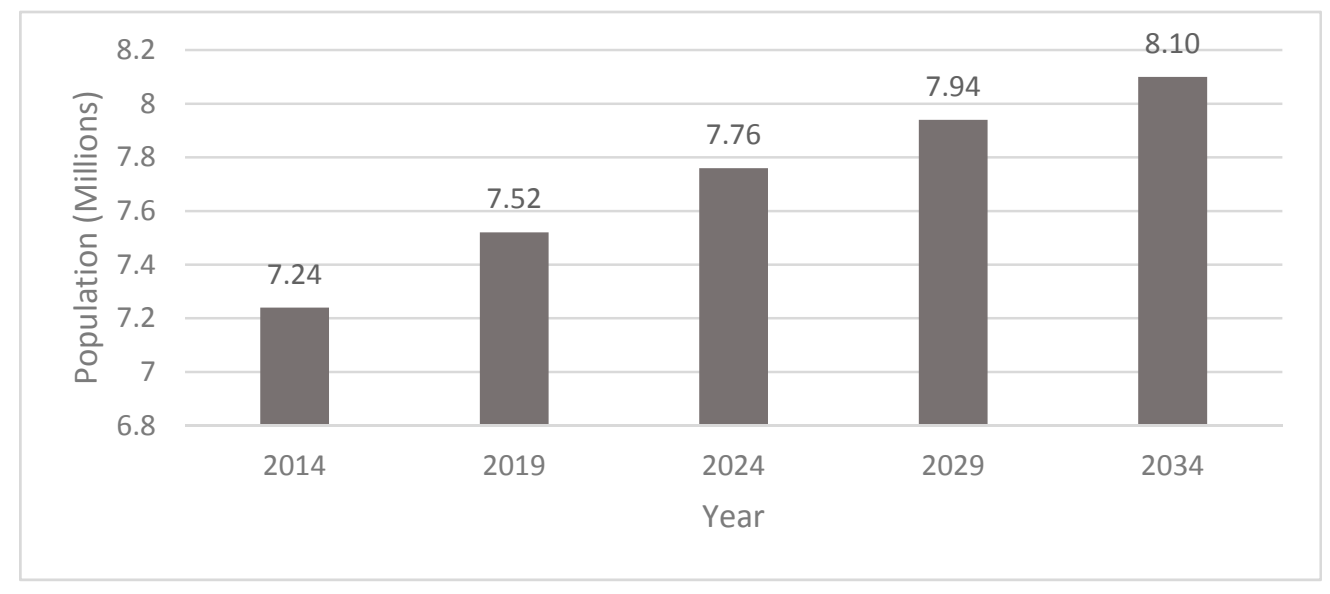

Figure 17. The growth rate of population in 2014, 2019, 2024, 2029, and 2034.

\section{Conclusions}

In this study, we presented an estimation of urban impervious surface in Hong Kong from Landsat TM satellite images using the V-H-L-S model and linear mixture analysis. High albedo, low albedo, soil, and vegetation were classified in the Landsat TM images, and the combination of high albedo and low albedo was considered the urban impervious surface. The reliability of the Landsat TM images (with 30-m spatial resolution) was reasonable and acceptable compared with the Google Earth images and our investigation.

In the process of impervious surface estimation, there were some constraints on the classification of endmembers from Landsat TM images. The shade on the Landsat TM images may have caused an error classification, which may have affected the results as well. Further development of image classification should be focused on handling this issue using high-resolution satellite images such as SPOT images (i.e., 10-m spatial resolution), which shall be used for the estimation of impervious surface in Hong Kong in the future.

The policy implications regarding conservation of the country parks, mountains and coastal protection areas are the key for the land use development in Hong Kong. Due to the protection policy, sustainable land use in Hong Kong is limited, but is observable in this study. The rate of 
increase for impervious surface area was low from 1995 to 2015, even though the rate of population growth was rapid. The strategies to increase the amount of available land to deal with the increasing population growth include building more pencil buildings and reclamation. In fact, these two strategies have limitations in the long term because the increasing number of pencil-thin buildings affects the temperature of the urban area greatly, accelerating the urban heat island problem, and it will probably result in public health issues. Moreover, the land from reclamation required a lengthy period of time for consolidation to enhance usability. Therefore, from a long-term view, it is still necessary to monitor impervious surface changes regarding the sustainability of coastal land use in Hong Kong.

Acknowledgments: The data from the website of USGS and from the local government of Hong Kong are highly appreciated. This research is jointly supported by the National Key Research and Development Program of China (Project Ref. No. 2016YFB0501501) and the Natural Scientific Foundation of China (41471353).

Author Contributions: Kapo Wong and Yuanzhi Zhang conceived, designed, performed the experiments, analyzed the data, and wrote the paper; Yu Li improved the data analysis; Jin Yeu Tsou contributed reagents/materials/analysis tools.

Conflicts of Interest: The authors declare no conflict of interest.

\section{References}

1. Bauer, M.E.; Heinert, N.J.; Doyle, J.K.; Yuan, F. Impervious surface mapping and change monitoring using Landsat remote sensing. In Proceedings of the ASPRS Annual Conference, Denver, CO, USA, 23-28 May 2004; American Society for Photogrammetry and Remote Sensing: Bethesda, MD, USA, 2004.

2. William Howard, E., Jr.; Morgan, C.W.; Masch, F.D. Study of Some Effects of Urbanization on Storm Runoff from a Small Watershed; Texas Water Development Board: Austin, TX, USA, 1966.

3. Wu, C.; Murray, A.T. Estimating impervious surface distribution by spectral mixture analysis. Remote. Sens. Environ. 2003, 84, 493-505. [CrossRef]

4. $\mathrm{Wu}, \mathrm{C}$. Normalized spectral mixture analysis for monitoring urban composition using ETM+ imagery. Remote Sens. Environ. 2004, 93, 480-492. [CrossRef]

5. Census and Statistics Department. Hong Kong Population Projections 2015-2064; Statistical Reports; Census and Statistics Department: Hong Kong, China, 2015.

6. Ridd, M.K. Exploring a V-I-S (vegetation-impervious surface-soil) model for urban ecosystem analysis through remote sensing: Comparative anatomy for cities. Int. J. Remote Sens. 1995, 16, 2165-2185. [CrossRef]

7. Lu, D.; Weng, Q. Spectral mixture analysis of the urban landscape in Indianapolis with Landsat ETM+ imagery. Photogramm. Eng. Remote Sens. 2004, 70, 1053-1062.

8. Weng, Q.; Lu, D. A sub-pixel analysis of urbanization effect on land surface temperature and its interplay with impervious surface and vegetation coverage in Indianapolis, United States. Int. J. Appl. Earth Obs. Geoinf. 2008, 10, 68-83. [CrossRef]

9. Lu, D.; Weng, Q. Use of impervious surface in urban land-use classification. Remote Sens. Environ. 2006, 102, 146-160. [CrossRef]

10. Wang, W.; Yao, X.; Zhai, J.; Ji, M. A Tetrahedron-Based Endmember Selection Approach for Urban Impervious Surface Mapping. PLoS ONE 2014. [CrossRef] [PubMed]

11. Hendrix, E.M.T.; Garcia, I.; Plaza, J.; Plaza, A. Minimum volume simplicial enclosure for spectral unmixing of remotely sensed hyperspectral data. In Proceedings of the Geoscience and Remote Sensing Symposium (IGERSS), Honolulu, HI, USA, 25-30 July 2010; pp. 193-196.

12. Deb, K.; Pratap, A.; Agarwal, S.; Meyarivan, T. A fast and elitist multiobjective genetic algorithm: NSGA-II. Evolutionary Computation. IEEE Trans. Evol. Comput. 2002, 6, 182-197. [CrossRef]

13. Vitousek, P.M. Global enviornmental change: An introduction. Annu. Rev. Plant Ecol. Syst. 1992, 23, 1-14. [CrossRef]

14. Lean, J.; Warilow, D.A. Slimulation of the regional climate impacts of Amarzon deforestation. Nature 1989, 342, 41-412. [CrossRef]

15. Shukla, J.; Nobre, C.; Sellers, P. Amazon deforestation and climate change. Science 1990, 247, 1322-1325. [CrossRef] [PubMed] 
16. Zhang, Y.; Zhang, H.; Lin, H. Improving the impervious surfaces estimation with combined use of optical and SAR remote sensing images. Remote Sens. Environ. 2014, 141, 155-167. [CrossRef]

17. Rashed, T.; Weeks, J.R.; Gadalla, M.S. Revealing the anatomy of cities through spectral mixture analysis of multispectral satellite imagery: A case study of the greater Cairo region, Egypt. Geocarto Int. 2001, 16, 5-15. [CrossRef]

18. Small, C. Multitemporal analysis of urban reflectance. Remote Sens. Environ. 2002, 81, 427-442. [CrossRef]

19. Hualin, X.; Yafen, H.; Xue, X. Exploring the factors influencing ecological land change for China's Beijing-Tianjin-Hebei Region using big data. J. Clean. Prod. 2017, 142, 677-687.

20. Guranrong, Y.; Hualin, X. Rural spatial restructuring inecologically fragile mountainous areas of Southern China: A case study of Changgang Town, Jiangxi Province. J. Rural Stud. 2016, 47, 435-448.

21. Hualin, X.; Guanrong, Y.; Guiying, L. Spatial evaluation of the ecological importance based on GIS for environmental management: A case study in Xingguo county of China. Ecol. Indic. 2015, 51, 3-12.

22. The Government of the Hong kong Special Administrative Region. Conservation. In Hong Kong Planning Standards and Guidelines; Technical Services Section of Planning Department: Hong Kong, China, 2012; Chapter 10.

23. Georgescu-Roegen, N. The Entropy Law and the Economic Process; Harvard University Press: Cambridge, MA, USA, 1971.

24. Daly, H.E. Beyond Growth: The Economics of Sustainable Development; Beacon Press: Boston, MA, USA, 1997.

25. FAO. FESLM: An International Framework for Evaluating Sustainable Land Management 1993. Available online: http://agris.faoswalim.org/resources/Land/sustainable_Land_Management_Evaluation_ Framework.pdf (accessed on 6 April 2017).

26. Chief of Staff of the Army; Strategic Studies Group; Megacities Concept Team. Megacities and the United States Army Preparing for a Complex and Uncertain Future. Available online: https://www.army.mil/e2/ c/downloads/351235.pdf (accessed on 21 September 2016).

27. Parker, D.; Mitchell, J.K. Disaster vulnerability of megacities: An expanding problem that requires rethinking and innovative response. GeoJournal 1995, 37, 295-301. [CrossRef]

28. Sorensen, J. The international proliferation of integrated coastal zone management efforts. Ocean Coast. Manag. 1993, 21, 46-80. [CrossRef]

29. Hong Kong Planning Department. 2015. Available online: http://www.pland.gov.hk/pland_en/index.html (accessed on 6 April 2017).

30. Roberts, D.A.; Gardner, M.M.; Church, R.; Ustin, S.; Scheer, G. Mapping chaparral in the Santa Monica Mountains using multiple endmember spectral mixture models. Remote Sens. Environ. 1998, 65, 267-279. [CrossRef]

31. Lu, D.; Batistella, M.; Moran, E.; Mausel, P. Application of spectral mixture analysis to Amazonian land-use and land-cover classification. Int. J. Remote Sens. 2004, 25, 5345-5358. [CrossRef]

32. Lu, D.; Moran, E.; Batistella, M. Linear mixture model applied to Amazonian vegetation classification. Remote Sens. Environ. 2003, 87, 456-469. [CrossRef]

33. Small, C. Estimation of urban vegetation abundance by spectral mixture analysis. Int. J. Remote Sens. 2001, 22, 1305-1334. [CrossRef]

34. Green, A.A.; Berman, M.; Switzer, P.; Craig, M.D. A transformation for ordering multispectral data in terms of image quality with implications for noise removal. IEEE Trans. Geosci. Remote Sens. 1988, 26, 65-74. [CrossRef]

35. Congalton, R.G. A review of assessing the accuracy of classifications of remotely sensed data. Remote Sens. Environ. 1991, 37, 35-46. [CrossRef]

36. Congalton, R.G.; Green, K. Assessing the Accuracy of Remotely Sensed Data: Principles and Practices; Lewis Publishers: Boca Raton, FL, USA, 1999.

37. Foody, G.M. Status of land cover classification accuracy assessment. Remote Sens. Environ. 2002, 80, $185-201$. [CrossRef]

38. Phinn, S.; Stanford, M.; Scarth, P.; Murray, A.T.; Shyy, P.T. Monitoring the composition of urban environments based on the vegetation-impervious surface-soil (VIS) model by subpixel analysis techniques. Int. J. Remote Sens. 2002, 23, 4131-4153. [CrossRef]

39. Theseira, M.A.; Thomas, G.; Taylor, J.C.; Gemmell, F.; Varjo, J. Sensitivity of mixture modeling to endmember selection. Int. J. Remote Sens. 2003, 24, 1559-1575. [CrossRef] 
40. Van der Meer, F.; de Jong, S.M. Improving the results of spectral unmixing of Landsat Thematic Mapper imagery by enhancing the orthogonality of end-members. Int. J. Remote Sens. 2000, 21, 2781-2797. [CrossRef]

41. Ji, M.; Jensen, J.R. Effectiveness of subpixel analysis in detecting and quantifying urban imperviousness from Landsat Thematic Mapper. Geocarto Int. 1999, 14, 31-39. [CrossRef]

42. Shaban, M.A.; Dikshit, O. Improvement of classification in urban areas by the use of textural features: The case study of Lucknow city, Uttar Pradesh. Int. J. Remote Sens. 2001, 22, 565-593. [CrossRef]

43. Weng, Q.; Lu, D.; Schubring, J. Estimation of land surface temperature-vegetation abundance relationship for urban heat island studies. Remote Sens. Environ. 2004, 89, 467-483. [CrossRef]

(C) 2017 by the authors. Licensee MDPI, Basel, Switzerland. This article is an open access article distributed under the terms and conditions of the Creative Commons Attribution (CC BY) license (http://creativecommons.org/licenses/by/4.0/). 